\title{
Impact of Sharing Economy Models on Energy Efficiency - Analysis of Ridesharing at European Level
}

\author{
Florin Pucheanu ${ }^{\star}$, Alexandru-Mihai Bugheanu ${ }^{\star \star}$, Ruxandra Dinulescu ${ }^{\star \star \star}$
}

\begin{tabular}{l}
\hline \multicolumn{1}{c}{ A R T I C L E I N F O } \\
\hline Article history: \\
Accepted November 2020 \\
Available online December 2020 \\
\hline JEL Classification \\
O52, Q43, E71 \\
Keywords: \\
Energy efficiency, Sharing \\
economy, Ridesharing, 4th \\
Industrial Revolution
\end{tabular}

\section{Introduction}

The increasing interest in technology innovations has heightened the need for digitalization and increased productivity. Specifically, the First Industrial Revolution began in England in the late 18th century and brought with it accelerated economic growth, based on steam-powered mechanization of production and transportation, promoting Capitalism as the dominant economic system on a global scale. Subsequently, with each wave of technology innovations, from centralized electricity grids to internal combustion engines, new industrial revolutions followed, which continuously increased the productivity and the efficiency of the economy. Nevertheless, the prevailing logic behind the production system, remained the same over the years, creating vertically organized manufacturing colossus able to generate mass production through economies of scale

The current paper presents the main aspects regarding the4th Industrial Revolution and the Collaborative Economy. Particularly, we are currently at the beginning of a technological revolution that by its magnitude, complexity and speed has no equivalent in history and promises to fundamentally transform the global economic and social system, becoming a vector of exponential growth in productivity. This paradigm, based on widespread digitalization and a combination of innovative technologies, which economists call the 4th Industrial Revolution, also promotes a new economic system, the Collaborative Economy.

One of the most significant current discussions brought by the Collaborative Economy is the replacement of vertical, rigid governance models, with their hierarchically organized production and distribution, with horizontal, self-organized networks of peers, which create and distribute value in a completely new approach.

Taking these things into consideration, the paper identifies this new paradigm. Such current pattern leads to a scaling up of the processes of generation and sharing of goods and services, between people completely unknown to each other, who can now coordinate their acquisition, distribution and consumption in a much more flexible way, increasing efficiency and dramatically reducing marginal cost, in some industries close to zero. 


\section{Literature review}

A considerable amount of literature has been published about sharing economy models. Nevertheless, in the last decades, a new series of research focus on a third element as an essential ingredient of growth: energy.

Firstly, the standard economic theory explains the advent of Capitalism as a synergy between two of its main pillars: capital and labor, which, according to classical economists, going all the way back to Adam Smith, represent the main source of economic growth.

Recent evidence suggests that most of the economic growth in the last two centuries has been due to a series of technological inventions, the so-called "general purpose technologies" whose effect has been a sustained increase in the efficiency of conversion of energy into useful work (Ayres, 2009).

To the extent that economic growth has been generated in the past by increasing the efficiency of energy conversion, it is important that the growth trend continues if possible, in the future.

Although this may be true, efficiency growth has certain natural and technological limits, and the historical trend has slowed considerably, so it is also important to find and integrate alternative catalysts with a wide impact in all sectors of the economy "[...] Information technology seems to be the only plausible candidate at the moment," concludes Ayres (2009).

Jeremy Rifkin (2015) examined a possible approach in this regard, stating that "[...] In a collaborative, fully digitalized economy, extreme productivity, generated by optimizing aggregate efficiency and reducing marginal cost close to zero, decreases the amount of information, energy, material resources, labor and logistics needed to produce, distribute and recycle goods and services".

A recent study by Klaus Schwab (2015) reports that the transition to the 4th Industrial Revolution, will represent a future critical production factor. Another key point, investigated by a large and growing body of literature are the economic and social innovations, arising from the creative and productive interactions of millions of people, through aggregative platforms of collaborative economy, facilitated by the new information and communication technologies.

As a matter of fact, the sharing of goods and services is by no means a new concept, being present in human societies since ancient times, as a deeply rooted part of our behavior and being studied in the literature under multiple approaches, from economic perspective to aspects related to social cohesion.

As a result, new economic and consumer practices, through collaborative and decentralized platforms, have received various names in the literature: co-production (Humphreys \& Grayson, 2008), prosumer networks (Ritzer \& Jurgenson, 2010), collaborative consumption (Botsman \& Rogers, 2010),), commercial sharing systems (Lamberton\& Rose, 2012) etc., but they all have in common two basic principles:

- A model focused mainly on the temporary access of the user to the respective good or service, and less on ownership.

- Intermediation and management are based on the Internet and are facilitated by information technology.

In their analysis of access-based consumption, Bardhi and Eckhardt (2012) accurately capture the motivation and principle behind the collaborative economy, noting that: "Instead of purchasing and owning, consumers prefer access to goods and services by agreeing to pay only for experience and temporary use".

The resulting platforms allow the productive interaction of millions of people, which generate energy, information and goods and services, at a marginal cost close to zero and share them with each other in the new collaborative or sharing economy (Rifkin, 2015).

However, Belk (2007) defines the sharing of goods and services as "the process of distributing what is ours to others, to be used, and the process of receiving and using something from others".

As can be seen, the difference that the collaborative economy facilitated by the new wave of information technologies brings, is the amazing scalability in terms of geographical coverage and number of people involved. It takes the sharing process out of a small circle of family and friends or small communities, and through trust enforcing mechanisms and matching algorithms it pushes the boundaries of value creation and distribution across continents.

\section{Research Methodology}

Taking into consideration that the sharing economy is an overarching approach rather than a homogenous phenomenon, Plewnia and Guenther (2018) suggested a classification for various sharing economy actions. This model illustrates four aspects, respectively the shared good (asks the question related to what is being shared), market orientation (assess also if a business model is oriented towards global or local markets or structured on online or offline platforms), market structure (conventional car sharing, Airbnb, Uber, etc) and the industry sector, more precisely, the place where the sharing activity occurs. The figure below presents a scheme of these sharing economy actions: 


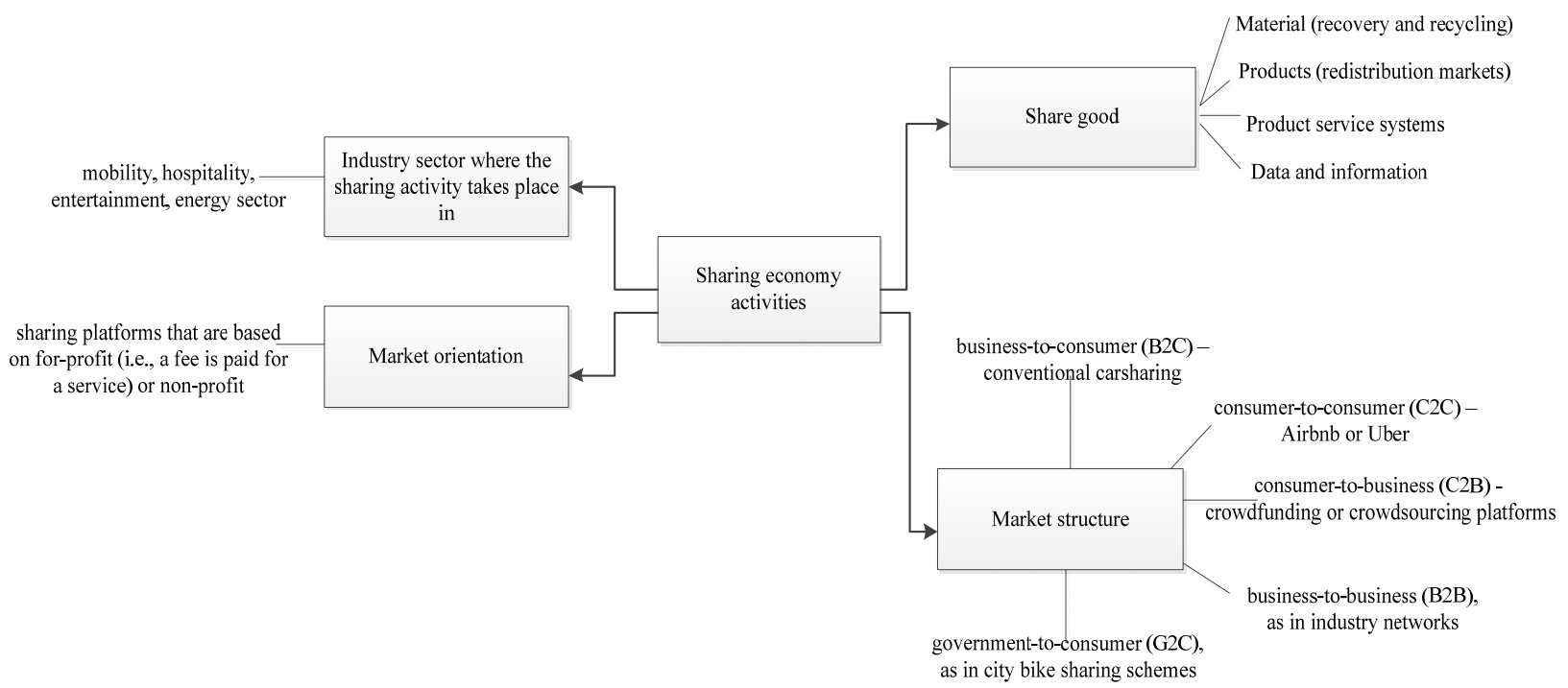

Figure 1. Sharing economy actions

Source: Adapted from Plewnia and Guenther (2018)

A recent survey applied in Bucharest on a one month period (August 2020), on a sample of 157 citizens (47\% of them were between 20 and 35 years old, $31 \%$ were between 36 and 50 years old, while $22 \%$ were over 50 years old) revealed the main used services via collaborative platforms:

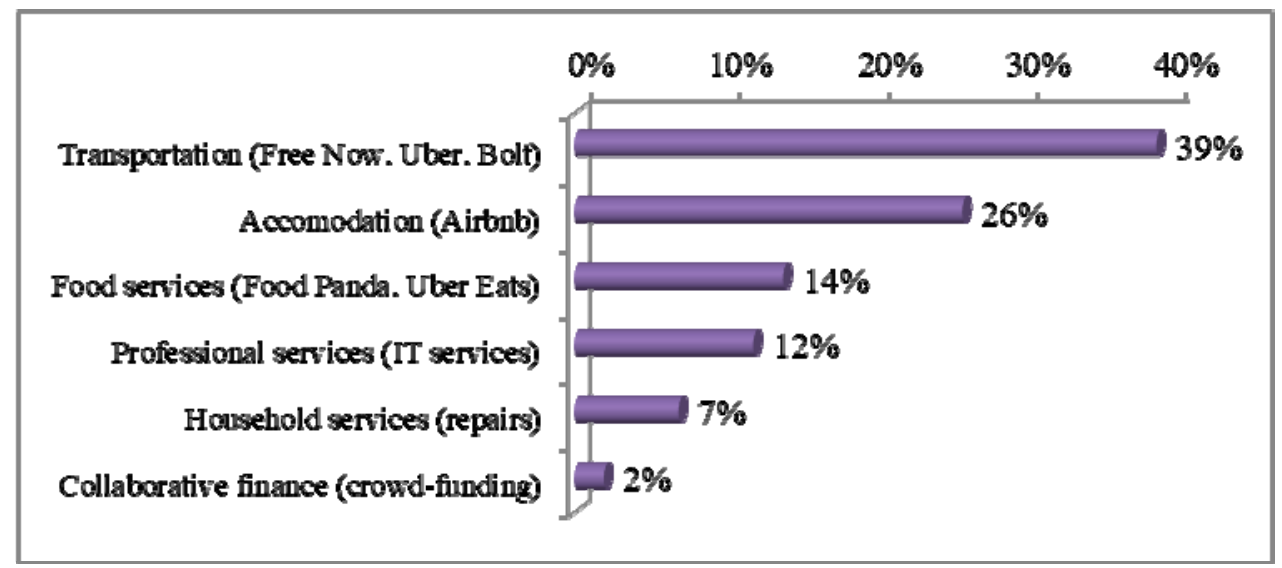

Figure 2. Services used via collaborative platforms

Source: The Authors

From the above figure it can be observed that the most frequently used collaborative platforms among the people interviewed is the transportation service. In Romania, the transportation platforms gained popularity, firstly with the ride-sharing services (Free Now, Uber, etc) and secondly, with the electric scooters derived from the same services.

Among the 157 respondents, 28 of them were in management functions. Therefore, we have asked them, which are the main advantages of using the collaborative platforms, from an economical point of view. Their answers can be seen below:

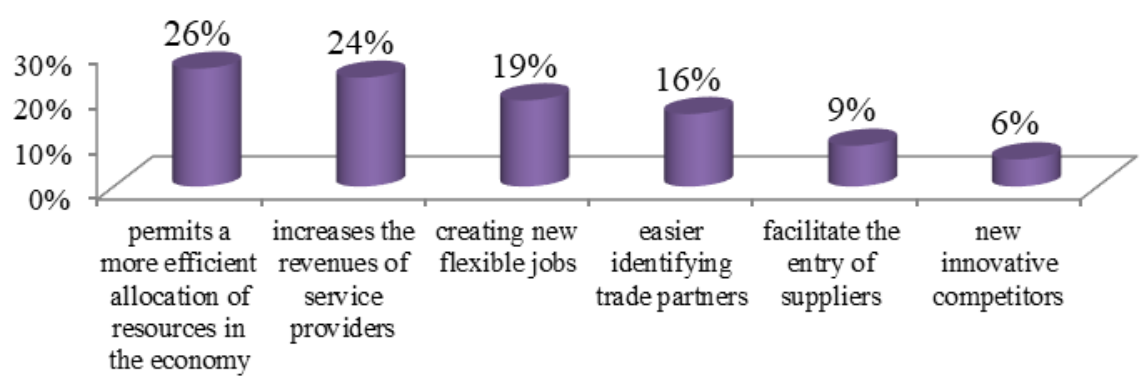

Figure 3. Advantages of using the collaborative platforms Source: The Authors 
From figure 3, it can be clearly stated that one of the main advantages, from an economical point of view, is the fact that the collaborative economy allows a more efficient manner of resource allocation in the economy. Also, $24 \%$ of the answers indicated as a second main advantage that the sharing models result in revenues increases for service providers.

The ridesharing market is forecasted to increase with an annual growth rate of $19.8 \%$ from 2018 to 2025 , reaching a market size of $\$ 218$ billion by 2025 . The main characteristics which lead to this increasing market are the need for personal mobility in the urban areas as well as the decreasing number of car ownership. Other important key factors are the growing internet penetration and significant $\mathrm{CO} 2$ decreasing target.

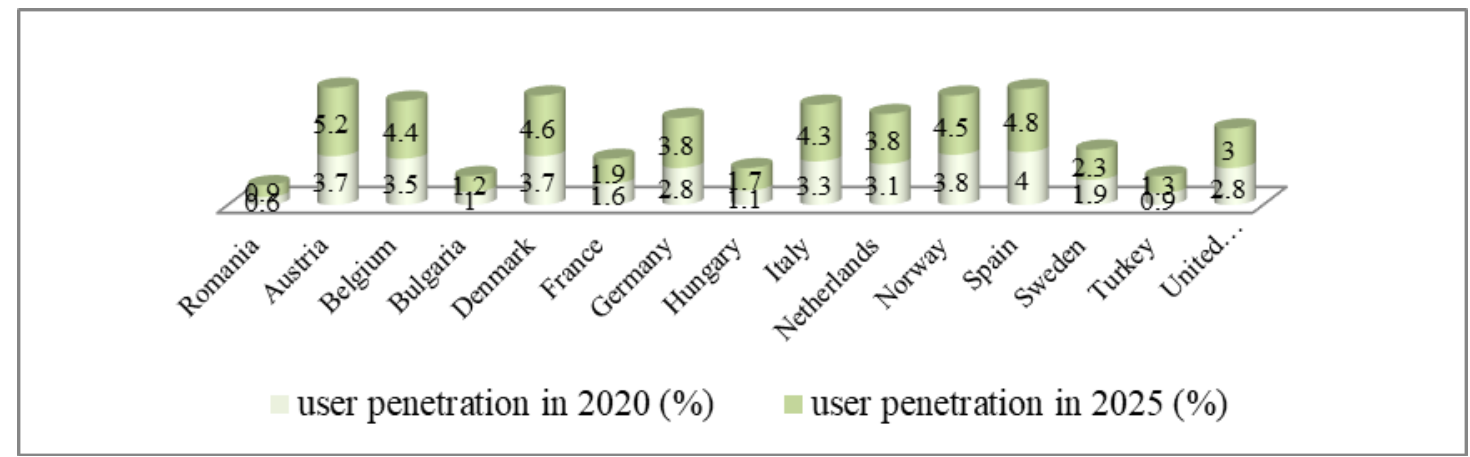

Figure 4. User penetration rate in 2020 versus 2025

Source: Data generated by the authors using www.statista.com

Figure 4 presents a comparison regarding the car-sharing market of the user penetration percent in 2020 and the expected user penetration increased percentage in 2025. As it can be clearly seen, in Austria the user penetration is, so far, $3.7 \%$ and is expected to arrive to $5.2 \%$ by the end of 2025 .

At the opposite corner, Romania has one of the lowest user penetration rates, of only $0.6 \%$ in 2020 with the prediction for 2025 not very different, of only $0.9 \%$. These small rates might be caused by the fact that the Romanian ride-sharing market did not meet the same success as in other European countries, at least not at the beginning. Romanians started to use the ride-sharing alternatives with a higher rate in 2018 and 2019 , the action being stopped at the beginning of 2020 due to the actual pandemic.

Regarding the revenue in 2020, after Bulgaria (with $\$ 4$ million), Romania has the lowest value, with only $\$ 8$ million so far. However, by the end of 2025 the ride-sharing revenue is expected to have a growth of $18.7 \%$. At the top of the ranking is situated United Kingdom (with a revenue of $\$ 574$ million in 2020) and Italy (with a revenue of $\$ 505$ million in 2025).

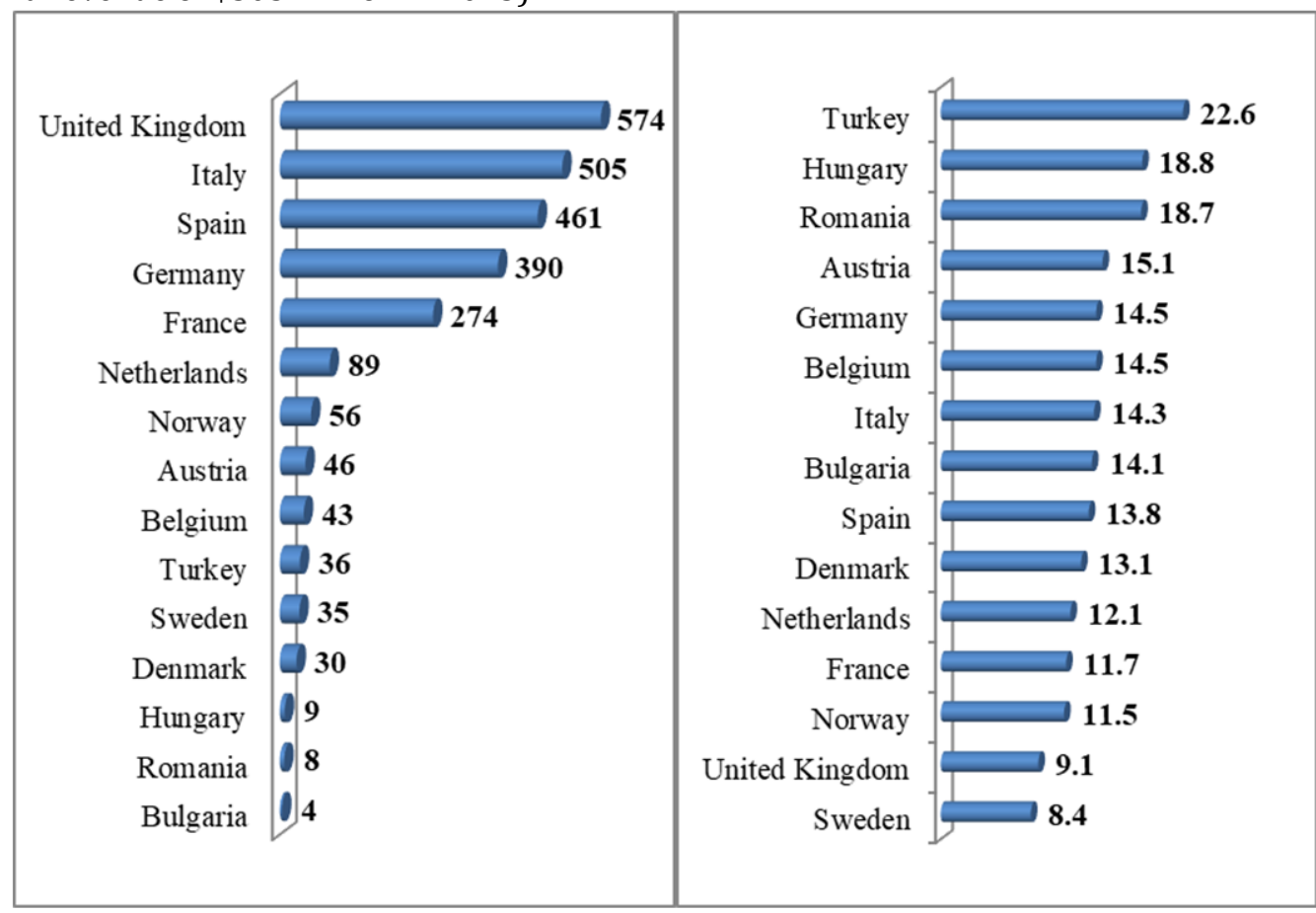

Figure 5. Revenue in 2020 (million \$) and expected growth in revenue (\%) by the end of 2025 Source: Data generated by the authors using www.statista.com 


\section{The importance of sharing models on energy conversion efficiency}

There is consensus among economists and researchers about the fact that, among other types of challenges, humanity is facing an energy efficiency problem, with the historical trend in advanced economies already stalling for decades. Being a generalized phenomenon, spreading across all industrialized countries, lead the economists into believing this might signal the approach of the current technological paradigm's limit and the trigger for searching and deploying new technologies able to boost the efficiency and thus the economic growth. According to Robert Ayres, the efficiency rate of conversion of energy into useful work in Japan has struggled for tens of years below the threshold of 20\%, while the one in the United States is barely pointing towards 15\%. According to a 2013 report of ACEEE (American Council for an Energy-efficient economy) „Of the total high-quality energy consumed to support economic activity in 2010, only 14 percent was converted into useful work. In other words, the American economy wasted 86 percent of all the energy used that year in the production of goods and services".

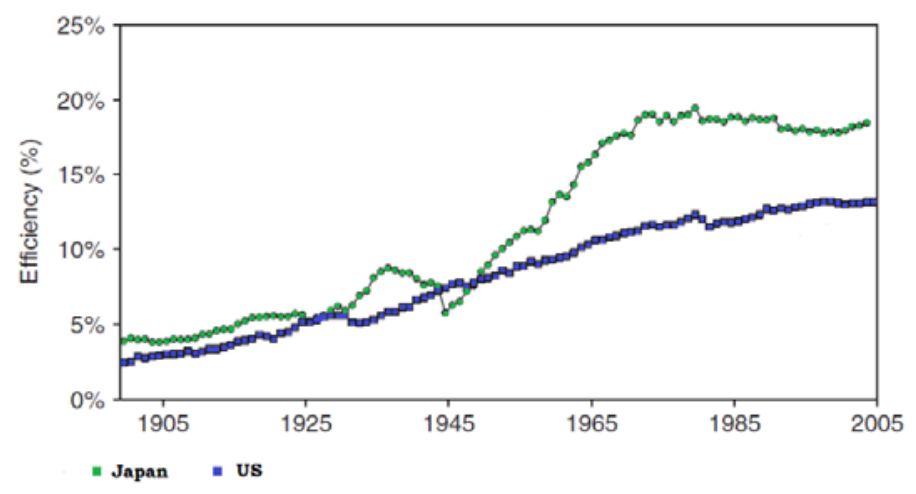

Figure 6. Aggregate efficiency of conversion of exergy to useful work for the us and Japan 1900 to 2005

Source: Ayres R.U., Warr B. (2009)

At European level, the Directive 2012/27/EU issued by the European Commission establishes a set of measures to put the EU economy on track towards reaching the 20\% energy efficiency target by 2020.This target implies a total energy consumption at EU level of maximum 1483 million tons of oil equivalent (Mtoe) of primary energy or 1086 Mtoe of final energy.

In 2018, the European Commission made a step forward by issuing a 'Clean energy for all Europeans package', which includes a new amending Directive on Energy Efficiency, that updates the policy framework for 2030 and beyond, with an ambitious energy efficiency target for 2030 of at least $32.5 \%$.

In absolute figures, this target translates to a maximum energy consumption of 1273Mtoe (million tons of equivalent) of primary energy and/or a maximum of 956 Mtoe of final energy, with the EU countries implementing measures to save on average $4.4 \%$ of their annual energy consumption between now and 2030 , all this without affecting the economic growth and prosperity of the European Union.

Nevertheless, in the last years, the EU's final energy consumption surpassed the indicative trajectory to meet both the 2020 and 2030 targets, with deviations in 2017 of $3.3 \%$ relative to the 2020 target and 17.4 $\%$ relative to the 2030 target. Preliminary estimates, not considering the effects of current Coronavirus crisis on economic shutdown and subsequent energy consumption, which are not documented and difficult to predict at this point in time, indicate levels that continue to exceed the indicative trajectories, targets achievement becoming increasingly uncertain.

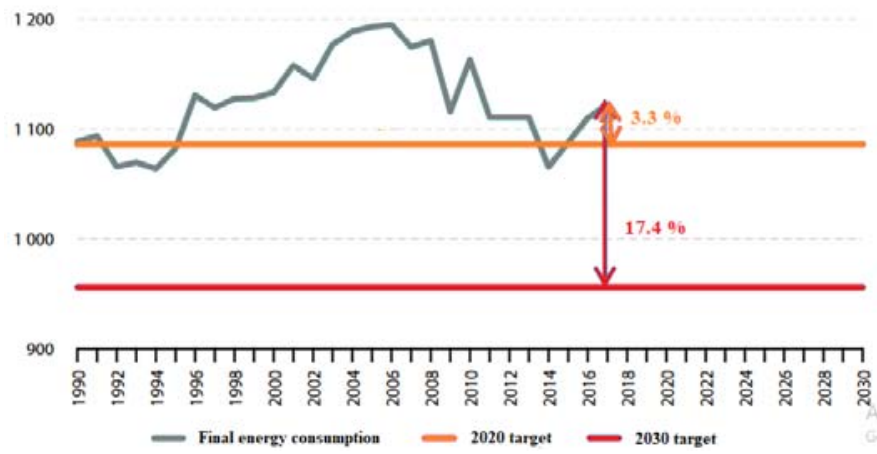

Figure 7. Distance to Europe 2020 and 2030 targets for final energy consumption, eu-28 Source: author adaptation from Eurostat, (2017) 


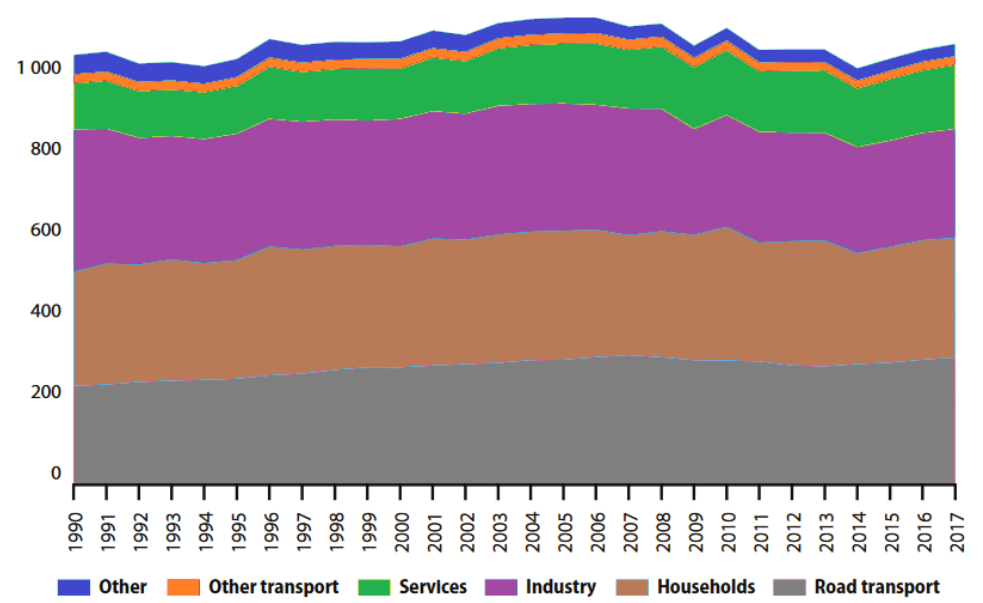

Figure 8. Final energy consumption, by sector, EU-28

Source: author adaptation from Eurostat, (2017)

According to Eurostat, in 2017, the transport sector represented the main consumption actor in the European Union, with $30,8 \%$ of total final energy consumption, followed by the households (27,2 \%), industry (24,6\%), services $(14,5 \%)$, agriculture and forestry $(2,3 \%)$ and other $(0,6 \%)$ sectors.

Moreover, road transport consumes the bulk of energy in the transport sector, standing for $73 \%$ of the total demand in 2017, registering an increase of $34 \%$ compared to 1990 levels, while historically in the EU, the passenger cars account for almost $50 \%$ of the energy consumption in transports.

So, the bottom line in the race to meet the energy efficiency targets is to find innovative ways of doing more in the economy with less energy spending.

Taking into consideration the transport sector consumes most of the energy at EU level, this article focuses on ways to improve transport energy efficiency, notably through a collaborative approach between the actors involved.

Public policies and research in the field of energy efficient and sustainable transport have proposed a series of measures ranging from increasing technical efficiency of vehicles to digitally improved traffic management, optimization of infrastructure use or increasing performance of multi-modal logistics chains. One thing is clear; in order to address such a complex and far-reaching problem as increasing the energy efficiency of transport, new and innovative approaches need to be considered, as the old pathways alone might not be enough to deliver the expected results. For example, focusing only on the incremental efficiency of vehicles will not be sufficient to deliver long-term benefits in terms of energy conversion efficiency or lowcarbon transport, due to inherent technical limitations or rebound effect.

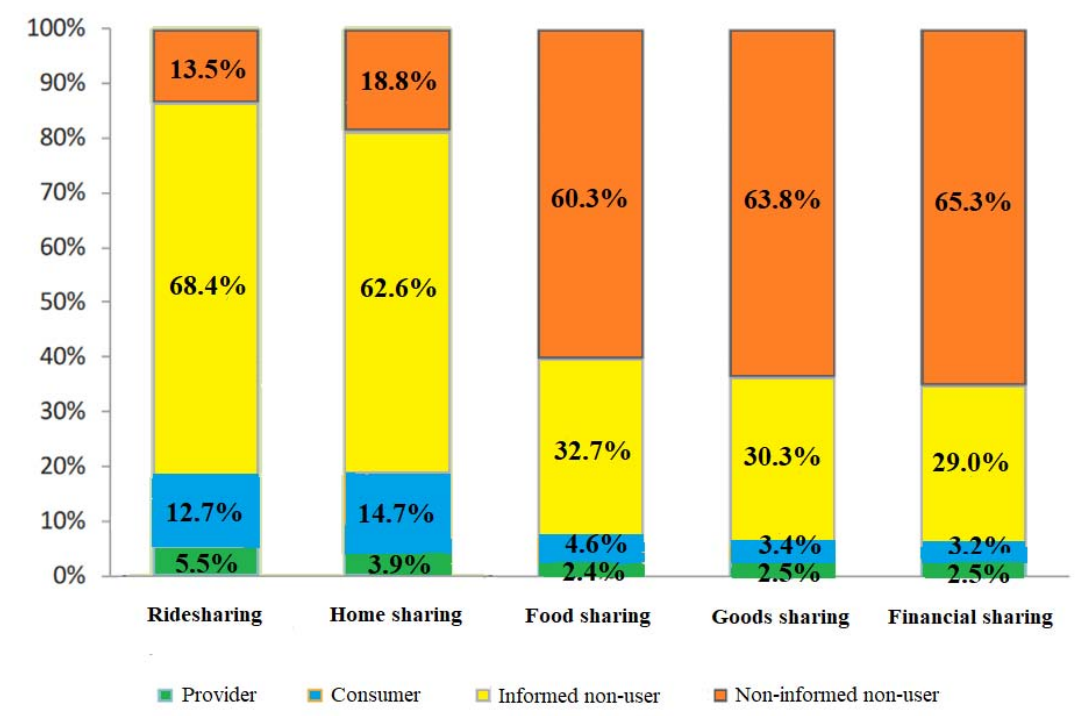

Figure 9. Predominant categories in the sharing economy in Europe Source: author adaptation from PWC Report, (2017) 
The sharing economy promises to solve part of the problems when it comes to optimizing and increasing the energy efficiency of transports. As the figure 9 shows, the ridesharing is the most popular form of collaborative economy among other categories in Europe. Due to its practical applications and advantages in terms of cost reduction and convenience, it has been embraced by $18,2 \%$ of population in an active manner. Even more important, and a source of future exponential growth, is the 68,4\% of the population which are already informed about this new phenomenon, and ready to participate with the right promotion and development of platforms.

\subsection{Data research and analysis}

Car occupancy plays a central role when looking at the passenger transport by car from a collaborative point of view and represents a key variable in assessing energy efficiency of transport.

Car occupancy is primarily a cultural and behavioral phenomenon, and can be influenced to a big extent by introduction of new trends, supported and adopted especially by younger generations, such as "Mobility as a Service", ridesharing, car sharing or autonomous vehicles. This is particularly important for urban environments, where most population concentrates, and where increased congestion and parking spots scarcity and costs in some urban areas may promote ridesharing as a more convenient and sustainable option in the future.

An increased occupancy rate would also increase energy efficiency of transport by moving more people around with less energy spending, while promoting other benefits for the environment or society like reducing emissions or traffic congestion and pollution with harmful particles. But unfortunately, the occupancy rate has fallen steadily for the last several decades, in the industrialized countries, due to the continuous reduction of household size and increase of number of vehicles per household for example. Today, there are sadly no examples of countries where the car occupancy is increasing.

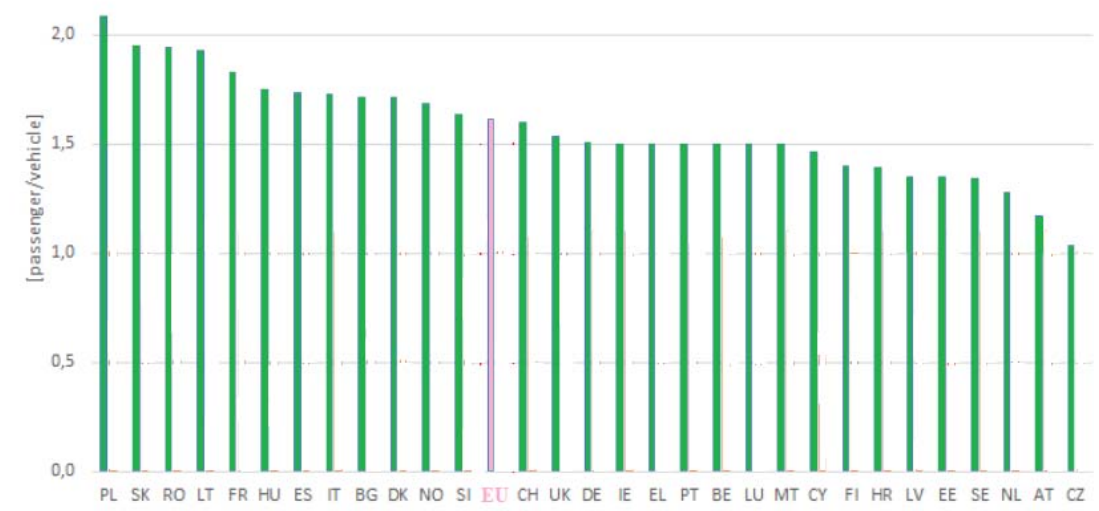

Figure 10. Occupancy in EU by country in 2015. Extrapolation based on traccs data.

Source: EUCALC Report

As depicted in Fig. 6, in 2015, the car occupancy levels in EU varied significantly from 2.1 persons/car in Poland to 1 person/car in Czech Republic, with an average occupancy level of 1.6 persons/vehicle for the EU28 + Switzerland area.

N. Levine \& M. Wachs (1996) identified a series of factors which directly influence car occupancy: Trip purpose (work related, educational, recreational, etc.); Day of week and time of day; Tripdistance; Geographic area; Traffic density in the area;

In terms of trip purpose, the car occupancy rates at EU level, as presented by IEA, stands as follows, depicting really low figures, well below the EU average, especially for daily commuters who tend to privilege a sort of "every man for himself" rule when it comes to work related trips.

\begin{tabular}{|l|c|}
\hline Travel purpose & Occupancy rate (passengers per vehicle) \\
\hline Commuting to/from work & $1.1-1.2$ \\
\hline Family trip & $1.4-1.7$ \\
\hline Travel and leisure & $1.6-2.0$ \\
\hline
\end{tabular}

Figure 11. Occupancy rates by travel purpose in Europe

Source: International Energy Agency

Also, extremely relevant for the current discussion is a report made by European Environment Agency, which emphasizes the distinction in occupancy rates between urban (1.3 passengers/car) and longdistance trips (1.8 passengers/car). 
It is intuitive and easily understandable that the occupancy rate is a starting point in every discussion about transport efficiency, but until recently, policy makers failed to propose effective measures to boost this indicator and determine people to voluntarily break the cultural and societal trends toward decreasing occupancy rates. Now, with the arrival of this new collaborative paradigm, and introduction and adoption of horizontal, flexible network of peers, the passenger transport landscape can witness a potential technological and societal revolution.

Ridesharing could be enabled in several different ways. First of all, technological break throughts, such as ubiquitous smart phone apps, make it easier for people to self-coordinate and participate to a wide array of collaborative platforms. Secondly, the mass dissemination of information about climate changes and ways in which the sharing economy can contribute to cutting the carbon footprint of human activities, might convince a big share of the $68 \%$ of informed non-users in the ridesharing at European level, to take concrete steps in this direction.

The calculation tree below, represents a simple formula for determining, based on certain inputs, the road passenger transport demand at EU level, expressed in vehicle-kilometers, a unit measure which shows in other words, the number of kilometers driven by all cars combined, in order to satisfy the population demand for mobility. The vehicle-kilometers indicator is in direct connection with the final energy consumption of transports, hence, the energy efficiency of transport. Part of the input variables are related to demographic and cultural realities, which have a very slow evolution in time, leaving the occupancy variable in this model as the key element to discuss on short term, for beneficially influencing the output result. It is obvious that the number of people travelling, or passenger-kilometer indicator, cannot register significant evolution over a short span, so the main driver for boosting the energy efficiency of passenger transport is the occupancy rate. Actually, it's simple math. If the same number of people travel around (pkm) using less vehicles (vkm) and thus energy, this directly translates into increased energy efficiency.

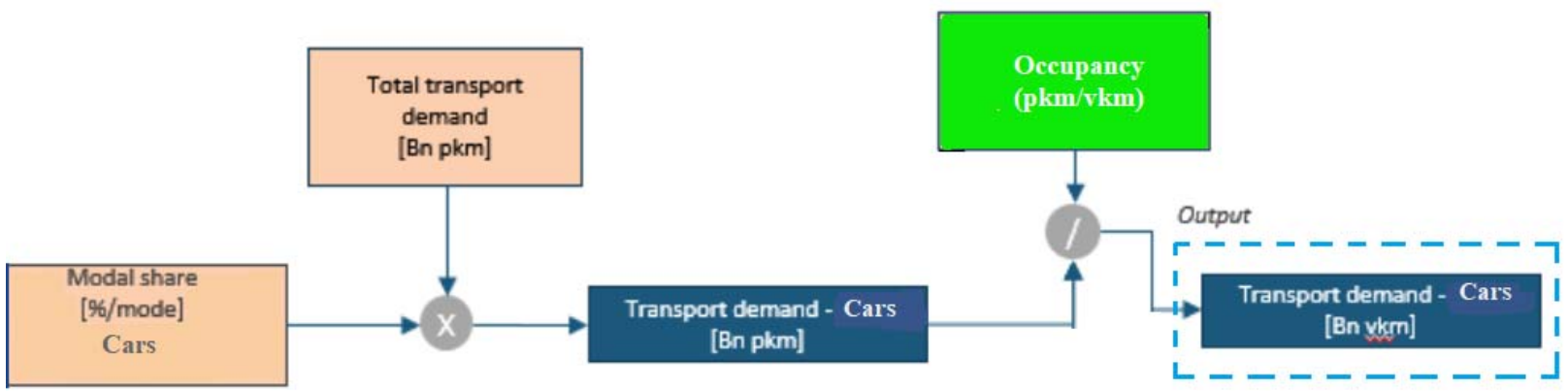

Figure 12. Calculation tree to determine the passenger transport activity.

Source: EUCALC Report, adaptation by author

Applying the above formula and using as inputs historical data about transport demand in the European Union and actual data and/or projections regarding occupancy rates for passenger cars, we can generate accurate results and estimates of different scenarios related to the energy efficiency targets.

For example, in 2015 at EU-28 level, with a total passenger transport demand of 6602 billion passengerkilometers (pkm) and a modal share of 71,5 \% for passenger cars, results a passenger transport demand of 4719 billion pkm. At an occupancy rate of 1,6 persons/car for the same year, results a car transport demand of 2949 billion vehicle-kilometers (vkm).

As according to Eurostat, the total energy consumption of all transport modes in the EU-28 amounted to 335 Mtoe (million tons of oil equivalent) in 2015 , and based on a share of around $60 \%$ for passenger cars in total transports calculated by IEA, we can draw the conclusion that this 2949 billion vkm accounts for approximately 201 Mtoe of final energy consumption.

Note that in 2015, the final energy consumption was 1088 Mtoe, breaking again above the 2020 target, after a short period, between 2013 and 2014, when the trend was below this threshold, pointing towards encouraging results.

If that year the occupancy rate of passenger cars would have been just 0,1 higher, standing at 1,7 persons/car, this would have led to a decrease of 174 billion vkm, from 2949 billion vkm to 2775 billion vkm. This, in turn would have generated a decrease of 12 Mtoe in the final energy consumption of transports that year, from 201 Mtoe to 189 Mtoe. With just this 12 Mtoe of energy savings, all other energy consumption factors remaining the same, the trend could have remained for the 3 rd year in a row below the 2020 energy consumption target.

In relation to 2017, when the trajectories to meet the energy efficiency targets were already missing 3,3 \% for 2020 target and respectively 17,4 \% for 2030 target, as discussed above, things become even more interesting when we look at them through the lenses of car occupancy.

With a passenger transport demand of 4901 billion pkm and the same occupancy rate of 1,6 persons/car, results a car transport demand of 3063 billion vkm. That year the total energy consumption of 
all transport modes being at 345 Mtoe, using the same calculation principle as above, we deduct that this 3063 billion vkm translates to approximately 207 Mtoe of energy.

At a total final energy consumption of 1122,3 Mtoe in 2017, and a target of 1086 for 2020, this 3,3\% deviation accounts for 36,3 Mtoe.

With an occupancy rate of 2 persons/car, the situation would look a lot different, decreasing the car transport demand from 3063 billion vkm to 2450 billion vkm, which applying simple math, would take the new passenger transport energy demand to 165,5 Mtoe, for an energy saving of 41,5 Mtoe, and successfully meeting the 2020 target.

Related to the 2030 target, of no more than 956 Mtoe of final energy consumption, the 17,4\% deviation of 2017 stands at 166,3 Mtoe. Of course, increasing the occupancy rate through ridesharing cannot be a silver bullet in the race towards 2030 target, and alone it cannot offset the energy consumption of all other sectors.

If we consider the share of the transport sector in the total final energy consumption, the 2030 target for the transport sector alone translates to 294,5 Mtoe of final energy consumption. In relation to 2017 final energy consumption in transports of 345 Mtoe, this gives a deviation of 50,5 Mtoe of final energy consumption, to be reduced for the transport sector to do its part in reaching the target.

Assuming the passenger transport demand remains constant, and a large scale deployment of ridesharing platforms across Europe would increase the car occupancy rate by just $0,1 \mathrm{pkm} / \mathrm{vkm}$ every year, it would take just 6 years for the passenger cars transport sector to offset the energy consumption of the whole transport sector and reach the 2030 target.

Table 1. Estimated energy efficiency gains according to car occupancy increase

\begin{tabular}{|c|c|c|c|c|}
\hline Year & $\begin{array}{l}\text { Occupancy rate } \\
\text { (pkm/vkm) }\end{array}$ & \begin{tabular}{l}
\multicolumn{2}{c}{ Passenger energy } \\
consumption $\quad$ (mtoe)
\end{tabular} & $\begin{array}{c}\text { Efficiency } \\
\text {-compared to 2017- } \\
\text { (mtoe) }\end{array}$ & $\begin{array}{l}\text { Final transport } \\
\text { energy consumption } \\
\text { (mtoe) }\end{array}$ \\
\hline 2018 & 1,7 & 194,8 & $-\quad 12,2$ & 332,8 \\
\hline 2019 & 1,8 & 184 & $-\quad 23$ & 322 \\
\hline 2020 & 1,9 & 174,3 & $\begin{array}{l}-\quad 32,7 \\
\end{array}$ & 312,3 \\
\hline 2021 & 2 & 165,6 & $\begin{array}{l}-\quad 41,4 \\
\end{array}$ & 303,6 \\
\hline 2022 & 2,1 & 157,7 & $\begin{array}{l}-49,3 \\
\end{array}$ & 295,7 \\
\hline 2023 & 2,2 & 150,5 & 56,5 & 288,5 \\
\hline
\end{tabular}

Figure 13 depicts the estimated trajectory of final energy consumption in the transport sector, taking into consideration the $0,1 \mathrm{pkm} / \mathrm{vkm}$ constant yearly increase in the car occupancy rate that we discussed above, which is plausible with a massive deployment of ridesharing platforms across Europe. With all other variables in the transport sector remaining unchanged, this improvement alone facilitates the achievement of the 2030 target, proportionally for the transport sector, by 2023.

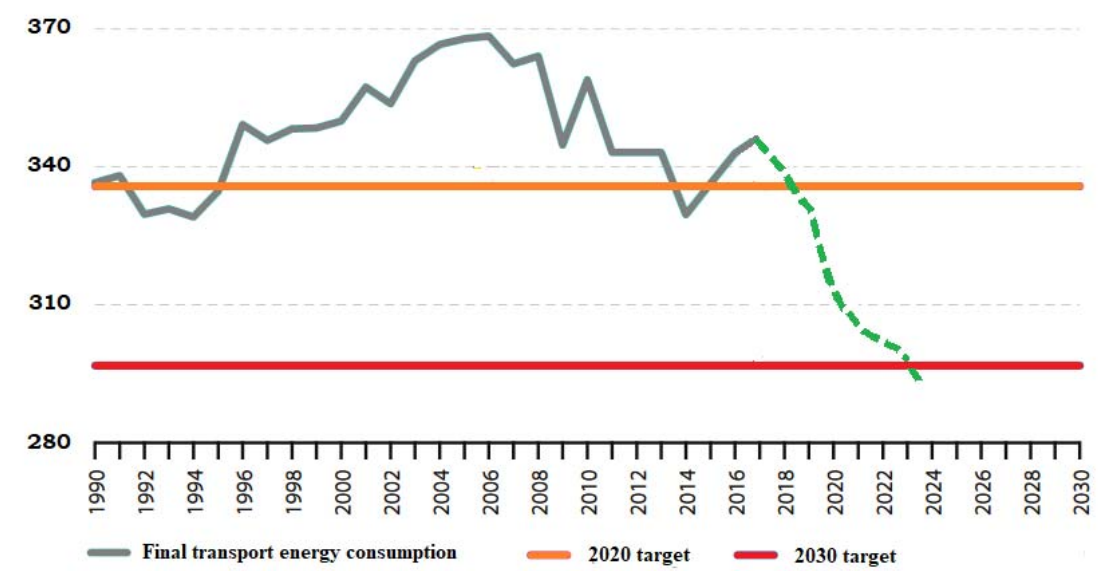

Figure 13. Final transport energy consumption estimated trajectory for a constant yearly increase of 0,1 PKM/VKM in occupancy rate

Source: The authors 


\section{Conclusions}

Nevertheless, one thing is clear. The sharing economy in general and the ridesharing sector, if efficiently enabled by the emerging information technologies and deployed at a great scale across Europe, has the potential to deeply disrupt the "business as usual" practices. This whole movement that is just beginning to take shape, promises to set the future on a sustainable path in transportation and other key sectors. But as any new paradigm, it comes with opportunities and with hurdles to overcome.

A study made by the Romanian Competition Council stated that about $12 \%$ of the citizens who use the internet over the last year, also used an accommodation service from different people in 2019, thus increasing the rate by $3 \%$ comparing to 2017. Also, in the European Union this percentage is equal to $24 \%$. Moreover, in 2018, 4\% of the total Romanian population used the transport services from other people, whilst the European Union's average is 8\% (http://www.consiliulconcurentei.ro/wpcontent/uploads/2020/06/dc-implicatiile_dezvoltarii_economiei_colaborative_sinteza_eng.pdf).

Of course, as in any other states, in Romania as well, the collaborative economy has its limits, one of the most significant being the dependency of the digital infrastructure. The idea of sharing is not new, being maybe of the oldest habits of humanity. Therefore, the present collaborative economy relies on connectivity, and thus a possible lack of internet access makes these kinds of transactions almost impossible. Even so, around the world, the urbanism rate increases more and more every year, thus a combination of high people density and better internet connection in cities, in the end, will result in an increase of the collaborative economy.

Based on the aspects discussed in this article, the evidence are that by effectively deploying collaborative platforms across Europe, a combined leverage effect can be generated, thus reducing the amount of cars on the roads, while exponentially increasing the number of people traveling around. In a world of growing populations and travel aspirations, increasing the efficiency of road travel can have a significant positive impact on both mobility and the environment.

As a further topic for study, we identify the need of more detailed analysis of different types of collaborative platforms, and especially ridesharing platforms, in terms of specific mechanisms of matching the offer and demand, and other particularities that might influence the efficiency and sustainability of the activities. Our intuition in this moment is that not all so called "ridesharing platforms" are constructed with a sustainability base in mind, nor attempting to integrate in their daily processes the famous "triple bottom line", which is one of the most important promises of the sharing economy.

\section{References}

1. Ayres R.U., Warr B. (2009), "Energy Efficiency and Economic Growth: the 'Rebound Effect' as a Driver", Herring H., Sorrell S. Energy Efficiency and Sustainable Consumption. Energy, Climate and the Environment Series. Palgrave Macmillan, London.

2. Bardhi, F., Eckhardt, G.M. (2012), "Access-Based Consumption: The Case of Car Sharing",

Journal of Consumer Research, 39(4), pp. 881-898.

3. Belk, R., (2007), "Why Not Share Rather Than Own?", Annals of the American Academy of Political and Social Science, 611 (1), pp. 126-140.

4. Benkler, Y., (2004), "Sharing Nicely: On Shareable Goods and the Emergence of Sharing as a Modality of Economic Production", The Yale Law Journal, 114(2), pp. 273-358.

5. Botsman, R., \& Rogers, R. (2010), “What's Mine Is Yours: The Rise of Collaborative Consumption", New York, NY: HarperBusiness.

6. Humphreys, A., \& Grayson, K. (2008), "The Intersecting Roles of Consumer and Producer: A Critical Perspective on Co-production, Cocreation and Prosumption", Sociology Compass, 2(1), pp. 808-1126.

7. Lamberton, C.P., Randall L. Rose (2012), "When is Ours Better than Mine? A Framework for understanding and Altering Participation in Commercial Sharing Systems", Journal of Marketing, 76 (4), pp. 109-125.

8. Rifkin, J., (2015), "Welcome to the Third Industrial Revolution", Wharton Magazine.

9. Ritzer, G., Jurgenson, N. (2010), "Production, Consumption, Prosumption the Nature of Capitalism in the Age of the Digital 'Prosumer",, Journal of Consumer Culture 10(1), pp. 13-36.

10. Schwab, K., (2015), "The Fourth Industrial Revolution.What It Means and How to Respond", Foreign Affairs. 